Neurosurgery 1983;13:136-40.

9 Royal College of Radiologists: costs and benefits of skull radiography for head injury. Lancet 1981;ii:791-5.

10 Thornbury JR, Campbell JA, Masters SJ, Fryback DG. Skull fracture and low risk of intracranial sequelae in minor head trauma. $A J R$ 1984;143:661-4

11 Boulis ZF, Dick R. Head injury in children. Aetiology, symptoms, physical findings and $\mathrm{x}$-ray wastage. $\mathrm{Br} \mathrm{J}$ Radiol 1978;51:851-4.

12 Masters SJ. Evaluation of head trauma: efficacy of skull films. AJR 1980;135:539-47.

13 Gibson TC. Skull x-rays in minor head injury. Scott Med J 1983;28:132-7.

14 Servadei F, Bastanelli S, Naccarato S, et al. Epidemiology and sequelae of head injury in San Marino Republic. J Neurosurg Sci 1985;4:297-303.
15 Teasdale G, Jennett B. Assessment of coma and impaired consciousness: a practical scale. Lancet 1974;ii:81-4.

16 Jennett B, Bond M. Assessment of outcome after severe brain damage: practical scale. Lancet 1977;i:873-81.

17 Hoff JT. Emergency skull x-ray films (Comment). Neurosurgery 1983;13:139.

18 Briggs M, Clarke $\mathrm{P}$, Crockard, et al. Guidelines for initial management after head injury in adults. Br Med $J$ 1984;288:983-5.

19 Bricolo P, Pasut LM. Extradural hematoma: toward zero mortality. Neurosurgery 1984;14:8-12.

20 Ciucci G, Servadei F, Rebucci GG, et al. (Head injuries in Ravenna: prospective study of hospitalized patients). Engl Abst Riv Pat Nerv Ment 1984;105:153-66.

21 Nelson EL, Melton JL, Annegers JF, Laws ER, Offord KP. Incidence of skull fracture in Olmstead County, Minnesota. Neurosurgery 1984;15:318-24.

\section{Parinaud's syndrome}

\section{A: Essential Paralysis of Convergence}

"... (a) Paralysis of the movement of convergence is indicated by two principal symptoms: the objectively appreciable defect of convergence and a peculiar diplopia... The diplopia appears in the median plane at a variable distance from the subject; it is crossed, and there is moderate separation of the images which persist without notable modification in all directions of looking... The images not infrequently become fused at four or five meters from the patient, a distance at which but little convergence is exercised, but cases do occur in which the diplopia persists at all ranges; ... (b) Accommodation is involved... in various ways. In certain cases there is absolute paralysis in both eyes; in others there is more or less notable reduction of its amplitude: whilst in a third class the accommodation is normal. (c) If in this form of paralysis there be no paralytic mydriasis, the pupillary reflexes are nevertheless modified... The reflex is abolished for convergence and retained for light, thus constituting a modification exactly inverse to that pointed out by Argyll Robertson as occurring in tabes".

\section{B: Combined Paralysis of Convergence}

"... The defect of convergence is accompanied by paralysis of elevation, and of depression in both eyes, with retention of lateral movements. This ... appears to be very rare in its complete form".

Parinaud H. Paralysis of the movement of convergence of the eyes. Brain 1886;9:330-41.
From the Tadhkirat of Ali ibn Isa of Baghdad (c. 940-1010 AD) ${ }^{1}$ an ancient description of what may be temporal arteritis.

"On Excision of Arteries and their Cauterization ... one treats not only migraine and headache in those patients that are subject to chronic eye disease but also acute, sharp, catarrhal affections, including those showing heat in and inflammation of the temporal muscles. These diseased conditions may terminate in loss of eyesight; frequently they are attended by a considerable degree of chemosis."

RT ROSS, MD

\section{Reference}

1 Memorandum Book of a Tenth-Century Oculist. A translation of the Tadhkirat of Ali ibn Isa (c. 940-1010 Ad)-translated by Casey A Wood. Chicago: Northwestern University Press, 1936:225. 